\title{
SPACE-TIME CONTINUUM OF THE OBJECT IN COGNITIVE PROCESSES OF NOMINATION
}

\author{
Olga P. Ryabko \\ Southern Federal University, Rostov-on-Don, Russian Federation
}

\begin{abstract}
The author's conception of flora nomination is based on consideration of modern flora names registered in the Oxford English dictionary and other lexicographical sources. The analysis is based on a fundamental statement about cognitive nomination being both of naive-cognitive character, thus reflecting personal knowledge of a nominator, and of science-cognitive nature, that is oriented on the system of academic knowledge; the methodological approach is comprised of statements of prototypical semantics, theme-rheme prominence theory, and the figure and background theory.

The flora names (floronyms) are observed as a macrofield that is subdivided on the basis of cognitive motivation in naming into parametric, pragmatic, and locative-temporal microfields.

The locative-and-temporal coordination between figure and background is reflected in location and time qualities of floronyms which explains their definition motivation and complicated naming structures. The locative qualities are presented in "nature locatives", they reflect naive-cognitive nomination, and "geographical locatives" that stand on science-cognitive basis. They define floronyms from the angle of their original micro- and macrovegetation placement. The temporal qualities of flora nomination point to human orientation in accordance with the chrono-and-time axis.

It is stated that locative-time names of flora give the evidence about nominator's spatial-and-temporal type of thinking, the research verified that locative-temporal nomination of plants is associated with space-time continuum.

Key words: cognitive nomination, naive-cognitive nomination, science-cognitive nomination, flora nomination, spatial feature, temporal feature, figure- background.
\end{abstract}

УДК 811.111

ББК 81.432 .1
Дата поступления статьи: 22.08.2016 Дата принятия статьи: 23.09.2016

\section{ПРОСТРАНСТВЕННО-ВРЕМЕННОЙ КОНТИНУУМ ОБЪЕКТА В КОГНИТИВНЫХ ПРОЦЕССАХ НОМИНАЦИИ}

\author{
Ольга Павловна Рябко \\ Южный федеральный университет, г. Ростов-на-Дону, Российская Федерация
}

\begin{abstract}
Аннотация. В статье предложена авторская концепция флоронимической номинации, разработанная на материале современных названий растений в английском языке. Ее теоретическую основу составило фундаментальное представление о когнитивной номинации как обыденно-когнитивной, производной от личностного знания номинатора, и научно-когнитивной, ориентированной на систему научных знаний, а методологическую базу сформировали положения прототипической семантики, теории рема-тематической выделенности и теории «фигура - фон».

Флоронимы описаны как макрополе, состоящее из трех микрополей (параметрического, прагматического и локативно-темпоративного), выделенных в соответствии с когнитивно-мотивационным признаком, ставшим основой номинации. В статье с учетом локативно-темпоративной отнесенности фигуры к фону подробно охарактеризованы локативно-темпоративные признаки, мотивирующие сложноструктурные флоронимические наименования, выявленные в ходе дефиниционного анализа соответствующих словарных статей Большого Оксфордского словаря (The Oxford English Dictionary) и других лексикографических источников. Локативные признаки дифференцированы на «природные локативы», отражающие в основном обыденно-когнитивную номинацию, и «географические локативы», отражающие в основном научно-когнитив-
\end{abstract}


О.П. Рябко. Пространственно-временной континуум объекта в когнитивных процессах номинации

ную номинацию. Они определяют флоронимическую номинацию с позиции ее адресной привязки в микрои макроадресных местах произрастания растений. Темпоративные признаки определяют флоронимическую номинацию с позиции адресной ориентации человека на хронотопной оси времени.

Установлено, что локативно-темпоративные наименования растений свидетельствуют о пространственно-временном мышлении номинаторов, и доказано, что локативно-темпоративная номинация растений представляет собой пространственно-временной континуум.

Ключевые слова: когнитивная номинация, обыденно-когнитивная номинация, научно-когнитивная номинация, флоронимическая номинация, пространственный признак, временной признак, «фигура - фон».

\section{1. Введение}

Когнитивная теория номинации имеет объектом своего исследования закономерности обыденно-когнитивной и научно-когнитивной номинаций. Процесс обыденно-когнитивной номинации зависит от личностного знания номинатора, которое не является общезначимым, общепринятым и потому выражается не концептуально, а, как правило, с опорой на непрямую / косвенную номинацию на основе метафорических и метонимических языковых средств. Научно-когнитивная номинация, напротив, является категориальной, объективно-ориентированной, использует средства прямой номинации, и сами научные понятия дискурсивно-логически определяются в качестве элементов конкретной научной системы знаний.

С целью представить авторскую концепцию флоронимической номинации в статье рассматриваются пространственные и временные мотивационные признаки наименований сложноструктурных флоронимов английского языка ${ }^{1}$. Их анализ проведен с использованием методологического арсенала теории фреймовой семантики, прототипической семантики, теории «фигура - фон» и ряда других.

Наименования растений можно структурировать как макрополе, включающее три признаковых микрополя: параметрическое, прагматическое и локативно-темпоративное. Выявляя и классифицируя мотивационно-номинативные признаки флоронимов, мы исходим из того, что номинатор находится в трехмерном пространстве - параметрическом, прагматическом и локативно-темпоративном [4]. Впечатления номинатора о внешнем виде растения, внешних свойствах, их перцептивное восприятие служат когнитивным основанием для параметрического наименования как результата обыденно-когнитивной номинации.
Прагматические суждения об особенностях растений, основанные на научных знаниях о мире, определяют признаковое наименование растений в рамках научно-когнитивной номинации. Локативно-темпоративные наименования растений свидетельствуют о пространственно-временном мышлении людей: при сравнении пространственно-временного номинативного потенциала растений и животных по степени охвата и детализации соответствующих реалий можно констатировать приоритетное место наименований растений $[3 ; 6]$.

Локативно-темпоративные наименования растений являются реляционными, поскольку признаки, фиксируемые в этих наименованиях, непосредственно не относятся к фенотипу растения. Они характеризуют внешнюю среду его произрастания, временные параметры роста, то есть его пространственно-временной континуум.

Рассмотрим подробно сложноструктурные номинации растений на основе локативно-темпоративного мотивационно-номинативного признака, при этом, во-первых, разграничивая локативные и темпоративные признаки, во-вторых, разделяя локативные флоронимы на образования с мотивационно-номинативным признаком «природный локатив» и образования с мотивационно-номинативным признаком «географический локатив».

Рассматриваемое локативно-темпоративное микрополе мотивационно-номинативных признаков сложноструктурных флоронимов английского языка основано на разграничении фона и фигуры, на необходимости локативно-временной «привязки» фигуры к фону. Флоронимическая номинация определяется с точки зрения ее адресной «привязки» к месту и времени произрастания растений.

Перспективным при анализе пространственно-временного континуума номинации 
растений является метод, предложенный в работе Б. Ландау «Where is what and what is where», в которой дается характеристика двум типам зрительных систем, получивших названия «что - системы» и «где - системы» [8] и служащих для распознавания и идентификации объектов в поле зрения. Эти системы различаются на основе противопоставления фона и фигуры. Фигура выделяется только на фоне, который несет пространственно-интегральную информацию, и тогда работает «что - система». Однако возможна коммуникативно-информативная инверсия фона и фигуры. В этом случае фигура приобретает интегральное значение и по существу становится фоном, а фон приобретает статус фигуры, то есть коммуникативноинформационной выделенности, тогда работает «где - система».

Изучая механизмы флоронимической номинации, мы исходим из того, что она организована по модели «фигура - фон». Растение обладает набором признаков, которые определяются как мотивационные признаки номинации. При этом можно разграничить фигурный мотивационный и фоновый мотивационный признаки. Фигурный признак рематически выделен, а совокупность фоновых признаков рематически не выделена.

\section{2. Номинация}

\section{на основе локативного признака}

Номинации, созданные на основе локативного признака, преобладают над номинациями, созданными на основе темпоративного признака.

Прежде чем перейти к их описанию, определим понимание категории «пространство», принятое в нашем исследовании. Научные представления о пространстве не связаны с постулатом о существовании вещественного мира предметов и объектов, однако на уровне обыденного сознания пространство, воспринимаемое как «пустота, потенциальное вместилище, которое может быть заполнено, но не обязательно должно быть заполнено» [2, с. 22], сопряжено с понятием места, которое имплицирует объект или предмет, а следовательно, «констатирует взаимосвязь пространства и объекта» [2, с. 22]. Именно поэтому в лингвистике говорят о локативных отношениях. Их обозначают одним термином «локум» - «пространство или предмет, относительно которого определяется местонахождение предмета, действия, признака и характер их взаимоотношений (статический или динамический)» $[1$, с. 6].

Категория «пространство» интерпретируется, таким образом, двояко: как собственно пространство и как пространство, репрезентируемое терминами «место» и «локум». Такая двойная интерпретация категории «пространство» позволяет не только противопоставить, но и объединить ее научное и обыденное понимание.

Действительно, научное сознание представляет локум / место как чистые формы созерцания, однако их интерпретация осуществляется за счет обыденных пространственных представлений места / локума. Вполне справедливо утверждение Е.С. Кубряковой о том, что «для наивной картины мира - а ведь язык отражает, в первую очередь, именно ее - верно скорее, что открытое пространство можно не только представить, но и увидеть» [2, с. 29].

Интерпретации категории «пространство» в работах других лингвистов, восходят к пониманию пространства по Ньютону и Лейбницу: различия сводятся к противопоставлению ньютоновского геометрического пространства пространству, определяемому «порядком осуществления вещей» [5, с. 228]. Ньютоновское пространство является некоторой объективацией идеи пространства, отвлечением от фактора восприятия пространства человеком. У Лейбница пространство «одушевляется〉 человеческим присутствием, оно относится к области человеческих представлений о мире, к «наивной философии мира» [7, c. 18]. По нашему мнению, эти интерпретации пространства дополняют друг друга, что позволяет принять их в совокупности при определении локативного признака, мотивирующего флористическое наименование.

Локативные флоронимы, как отмечено выше, подразделяются на природные и географические, отличаясь друг от друга формами номинации, типами номинации, когнитивными основаниями, семантической выделенностью «фигура - фон». 
О.П. Рябко. Пространственно-временной континуум объекта в когнитивных процессах номинации

Сложноструктурные флоронимические образования с мотивационно-номинативным признаком «природный локатив» подразделяются на эндоцентрические и экзоцентрические образования в рамках прямой и непрямой / косвенной номинации. Их когнитивное основание определяется зрительным восприятием мира растений, выражая адресное произрастание растений по природным локусам: моря, заливы, озера, реки, горы, равнины, леса, луга, болота и другие ареалы.

Приведем, прежде всего, ряд дефиниционных примеров прямых номинаций, извлеченных методом сплошной выборки из Большого Оксфордского словаря, с указанием природных локативов: sea-grass - «a grass which grows by the sea, one of various grass-like plants, such as, sea-pink and one of various plants and sea-weeds growing in the sea, as pondweed, gulf-weed»; swamp-oak - «in North America a name for several species of an oak growing in swamps»; marsh-mallow - «a shrubby herb Aethea officinalis which grows near salt marshes»; mountain larch - «a kind of fir Larixlyalli native of rocky mountains»; rockplant - «a plant that grows upon or among rocks, e. g. the rock-plant with but one leaf, the root grows out of the rocks»).

В функции природного локативного модификатора сложноструктурных флоронимических образований дефиниционная статья Большого Оксфордского словаря представляет и лексему meadow: «meadow-prefixed to names of plants to denote varieties or species growing in meadows, as meadow clover, meadow dock, meadow pea, meadow sage». Аналогичным образом дефиниционные статьи указанного словаря представляют лексемы wood: «wood in names of plants or their products growing in woods», например, wood anemone: «Anemona nemorosa abundant in woods and blossoming in early spring»; heath: «in names of trees and plants is applied to any species which grows on heath, such as, Fhumus, Calomacus, Paliurus»; river: «is used attributively with names of trees, plants», например, river-tree - «it always grows on the banks and shoots its root on the water». Идентично фоновую привязку к месту произрастания растений передают модификаторные лексемы: wall - «in the names of plants growing on or by walls and in dry stony places, e. g. wall-cress, wall-grass, wall-weed, etc.»; stone - «stone in names of plants means growing in stony places, such as, stone-bramble, stone-fern, stone-lichen, stone-weed». Признаковое модификаторное присутствие в сложноструктурных флоронимических образованиях определяет и лексема sand, например, sand-bur - «any one of several plants abounding in the sandy districts and great planes of Western U.S., the fruit of which becomes a bur»y.

В качестве природных локативных модификаторов выступают и менее репрезентативные лексемы field, prairie, moss, cape, ridge, savannah, имеющие реляционное дефиниционное описание: «field in names of plants growing in the fields, e. g., field forget-me-not, field scabious»; лексема prairie - «for any grass growing on the prairies, such as, prairie-burdock, prairie-clover, prairie-rose, etc.»; лексема moss «in names of plants growing in mosses, e. g., moss-whin, moss-pink»; лексема cape - «in names of plants, such as, cape-holly, cape-jasmine, cape marigold, etc.». Минимальную фоновую репрезентативность имеют следующие лексемы, определяющие модификатор сложноструктурных флоронимических образований с номинативным признаком «природный локатив»: bog (-pimpernel), castle (-gillyflower), country (-pepper), forest (-mahogany), gulf (weed), highland (-pine), lake (-weed), lowland (-sweetwood), park (-shrub) и значительный ряд других лексем.

Косвеннономинативные модификаторные лексемы, передающие когнитивный признак «природный локатив», характеризуют разные референтные области, в связи с чем можно выделить: «растительный локатив», например, corn-flower - «a name given to various plants commonly found growing among corn»; «животный локатив», например, rattlesnake-fern - «the Moonwort is named so on account of its generally being found where those reptiles abound $» ;$; «исторический локатив», например, Saracen corn - «Fagopurumes culentium used by Saracens-Normadic peoples of the Syroarabian desert» и «артефактный локатив», например, pot-tree - «a tree grown in a pot».

Рассмотрим сложные флоронимические образования с мотивационно-номинативным признаком «географический локатив», которые характеризуют номинацию с точки зрения ее 
адресной «привязки» к макроадресным местам произрастания растений. Такие флоронимы являются продуктами научно-когнитивной номинации, результатом длительной научной работы ученых-ботаников, фармакологов, биологов, историков, филологов. Мотивационнономинативный признак флоронимов «географический локатив» может быть реализован поразному. Во-первых, он представлен в адъективных образованиях, в которых модификаторные лексемы - это названия разных стран произрастания растений, например, French rhubarb - «any of various species cultivated in France»; Scotch grass - «plants cultivated in all the low and marshy lands of Scotland»; во-вторых, он представлен в образованиях, в которых модификаторные лексемы - это названия островов и полуостровов например, Madeira (-mahogany), Barbadoes (-cherry), Molucca (-balm), Bermuda (-cedar), Isle of man (-cabbage), Isle of Wight (-wine), Tahiti Island (-gooseberry) и др.; в-третьих, он представлен в образованиях, в которых модификаторными лексемами являются наименования городов, расположенных в разных странах, например, Jafa (-moss), Marseilles (-vinegar), Riga (-pine), Boston (-ivy), Granada (yam), и наименованием штатов, например, Virginia (-cedar), Carolina (-allspice), California (-holly), Arkansas (-cabbage), Florida (-moss).

\section{3. Номинация}

\section{на основе темпоративного признака}

Темпоративные признаки, определяющие модификатор сложноструктурных флоронимов, классифицируются на разграничении фона и фигуры, на необходимости временной «привязки» фигуры к фону. Они продукт адресной ориентации номинатора на хронотопной оси времени. Флоронимические наименования с мотивационно-номинативным признаком «темпоратив» являются древнейшими, как и природно-локативные наименования. Их возникновение было связано с практическими, хозяйственными потребностями носителей языка, поскольку темпоративные наименования отражают время сбора урожая и праздники, связанные с этими событиями.
Флоронимические наименования с мотивационно-номинативным признаком «темпоратив» подразделяются на прямономинативные и косвеннономинативные. Прямономинативные темпоративные флоронимические наименования привязаны к объективным показателям времени: временам года, месяцам года, времени суток. Временные референты могут маркироваться в терминах косвенной номинации, поскольку могут соотносится с определенными народными и религиозными праздниками, отражая когнитивный пласт флоронимической номинации. Темпоративные флоронимы в силу их релятивного характера тесно смыкаются с локативными признаками, отражая пространственно-временной континуум флоронимической номинации.

Рассмотрим в репрезентативном порядке флоронимические наименования с мотивационно-номинативным признаком «темпоратив». Он реализуется, во-первых, в фигурных наименованиях годовых сезонов созревания и роста растений. Прямономинативно данный признак передается лексемами winter, spring, summer, autumn, например, winter corn - «corn sown in winter or in autumn and remaining in the ground through the winter»; spring-grass «Anthoxan thumadoratum, a grass which appears in early spring»; summer fruit - «a name applied to crops that ripen in summer»; autumn dandelion - «a plant which flourishes in autumn».

Косвеннономинативный признак «темпоратив» передается лексемами lent, gang, cross, которые характеризуют религиозные праздники, устои, правила, связанные в сознании номинатора с определенным временем года. Например: lent-grain - «the two plants: barley and peasel, as well as, oats are called lentgrains, as being to be sown about Lent time the spring crops»; cross-flower - «Polygala a wort specially does flourish in the Cross or Rogation week»; gang-flower - «the Milkwort which flourishes in the Cross or Rogation week».

Во-вторых, мотивационный признак «темпоратив» прямо выражен в наименованиях с ориентацией на название месяца. Чаще других использовано название месяца Мay, например, Mayflower - «an flower that blooms in May, used locally as a specific name for various 
О.П. Рябко. Пространственно-временной континуум объекта в когнитивных процессах номинации

plants, such as, cowslip, Lady's smoke»; а также названия летних месяцев June (-berry, -grass, -apple), July (-flower, -grape). Темпоративный признак во флоронимических наименованиях может быть передан и в косвенной номинации. При этом референция месяца выражается именами собственными и именами религиозных деятелей, названиями религиозных праздников. Например: St. Michael pear - «а kind of pear that is ripe at Michaelmas - the feast at St. Michael on the $29^{\text {th }}$ of September»; Christmas-rose - «a species of Hellebore with large white flowers commonly cultivated in gardens, in bloom from December to February»; John-apple - «a fruit plant, so called because it is ripe about St. John's Day».

B-третьих, мотивационный признак «темпоратив» прямо называется модификаторными лексемами со значением времени суток. Чаще других используются лексемы day, midday и night, например, day-flower - «а flower that opens by day, spiderwort, and closes in the night»; midday-flower - «a flower which opens its flowers only for a short time at midday»; night primerose - «the plant is so called because its flowers usually are opened between six and seven o'clock in the evening».

\section{4. Выводы}

Флоронимы в английском языке образуют макрополе, состоящее из параметрического, прагматического и локативно-темпоративного микрополей, которые выделены нами в соответствии с когнитивно-мотивационным признаком, положенным в основу номинации того или иного растения. Анализ локативно-темпоративных признаков, мотивирующих сложноструктурные флоронимические наименования, проведенный с учетом локативно-темпоративной отнесенности фигуры к фону, позволил разделить их на «природный локатив», «географический локатив» и «темпоратив».

Мотивационная структура флоронимических наименований с мотивационным признаком «природный локатив» отражает обыденно-когнитивное представление о мире растений с точки зрения их адресной привязки, показывая, в какой местности проживали носители английского языка и насколько важен был для них контакт с окружающей средой. Флоронимические наименования с мотивационным признаком «географический локатив» - часть более позднего пласта наименований растений в рамках научной когнитивной номинации. Данные наименования появились благодаря морским путешествиям, географическим открытиям, ознакомлению англичан с новыми странами. Таким образом, флоронимы с мотивационным признаком «природный локатив» относятся к более древнему типу номинации по сравнению с более поздним продуктом номинативной деятельности человека - флоронимами с мотивационным признаком «географический локатив».

Флоронимические наименования с мотивационным признаком «темпоратив» привязаны к объективным показателям времени. Они градуированы на временной хронотопной шкале - времена года, суток, названия месяцев. Временные референты флоронимических наименований привязаны и к определенным религиозным праздникам, времени посева и сбора урожая, отражая когнитивный пласт темпоративной номинации.

Таким образом, локативно-темпоративные мотивационно-номинативные признаки флоронимических наименований характеризуют номинацию в рамках пространственно-временного континуума.

\section{ПРИМЕЧАНИЕ}

${ }^{1}$ Источниками для отбора фактического материала послужили следующие издания:

Рябко, О. П. Англо-латинско-русский ботанический словарь. - Ростов н/Д : Изд-во Рост. ун-та 1995. $-640 \mathrm{c}$.

The Oxford English Dictionary. - Oxford, 1933. - Vol. 1-12. - Electronic data. - Mode of access: https://www.oxforddictionaries.com/. - Title from screen.

The Oxford English Dictionary. - A supplement to the Oxford English Dictionary. - Oxford, 1972. Vol. 1. - Electronic data. - Mode of access: https:// www.oxforddictionaries.com/. - Title from screen.

The Oxford English Dictionary. - A supplement to the Oxford English Dictionary. - Oxford, 1976. Vol. 2. - Electronic data. - Mode of access: https:// www.oxforddictionaries.com/. - Title from screen.

The Oxford English Dictionary. - A supplement to the Oxford English Dictionary. - Oxford, 1982. - 
Vol. 3. - Electronic data. - Mode of access: https:// www.oxforddictionaries.com/. - Title from screen.

The Oxford English Dictionary. - A supplement to the Oxford English Dictionary. - Oxford, 1986. Vol. 4. - Electronic data. - Mode of access: https:// www.oxforddictionaries.com/. - Title from screen.

\section{СПИСОК ЛИТЕРАТУРЫ}

1. Всеволодова, М. В. Способы выражения пространственных отношений в современном русском языке / М. В. Всеволодова, Е. Ю. Владимирский. - М. : Русский язык, 1982. - 264 с.

2. Кубрякова, Е. С. Язык пространства и пространство языка (к постановке проблемы) / Е. С. Кубрякова // Известия РАН. Серия литературы и языка. 1997. - Т. 56, № 3. - С. 22-31.

3. Рукина, Э. П. Структурно-семантические особенности наименований австралийской орнитофауны : автореф. дис. ... канд. филол. наук / Рукина Эмма Петровна. - Киев, 1976. - 34 с.

4. Рябко, О. П. Сложноструктурные флоронимы английского языка / О. П. Рябко. - Ростов н/Д : Изд-во Рост. ун-та, 2002. - 320 с.

5. Топоров, В. Н. Пространство и текст / В. Н. Топоров // Текст: семантика и структура / отв. ред. Т. В. Цивьян. - М. : Наука, 1983. - С. 227-284.

6. Шамлиди, Е. Ю. Структурно-семантические и словообразовательные особенности двухкомпонентных зоосемических наименований (опыт теории словообразовательной номинации) : автореф. дис. ... канд. филол. наук / Шамлиди Евгений Юрьевич. - М., 1979. - 24 с.

7. Яковлева, Е. С. Фрагменты русской языковой картины мира (модели пространства, времени и восприятия) / Е. С. Яковлева. - М. : Гнозис, 1994. $344 \mathrm{c}$.

8. Landau, B. Where is what and what is where: The Language of objects in space / B. Landau // Lingua. 1994. - Vol. 82. - P. 259-296.

\section{REFERENCES}

1. Vsevolodova M.V., Vladimirskiy E.Yu. Sposoby vyrazheniya prostranstvennykh otnosheniy $v$ sovremennom russkom yazyke [The Ways of Expressing Spatial Relations in Modern Russian Language]. Moscow, Russkiy yazyk Publ.,1982. 264 p.

2. Kubryakova E.S. Yazyk prostranstva i prostranstvo yazyka ( $\mathrm{k}$ postanovke problemy) [Language of the Space and the Space of Language (to the Problem Statement)]. Izvestiya RAN. Seriya literatury i yazyka, 1997, vol. 56, no. 3, pp. 22-31.

3. Rukina E.P. Strukturno-semanticheskie osobennosti naimenovaniy avstraliyskoy ornitofauny: avtoref. dis. ... kand. filol. nauk [Structural-Semantic Features of Australian Avifauna. Cand. philol. sci. abs. diss.]. Kiev, 1976. 34 p.

4. Ryabko O.P. Slozhnostrukturnye floronimy angliyskogo yazyka [Compound-Structured Flora Names in the English Language]. Rostov-on-Don, Izdvo Rostovskogo un-ta, 2002. 320 p.

5. Toporov V.N. Prostranstvo i tekst [Space and Text]. Tsivyan T.V., ed. Tekst: semantika i struktura [Text: Semantics and Structure]. Moscow, Nauka Publ., 1983, pp. 227-284.

6. Shamlidi E.Y. Strukturno-semanticheskie $i$ slovoobrazovatelnye osobennosti dvukhkomponentnykh zoosemicheskikh naimenovaniy (opyt teorii slovoobrazovatelnoy nominatsii): avtoref. dis. ... kand. filol. nauk [Structural-Semantic and Word-Formation Features of Two-Component Zoosemantic Names (the Experience of Nomination Theory). Cand. philol. sci. abs. diss.]. Moscow, 1979. 24 p.

7. Yakovleva E.S. Fragmenty russkoy yazykovoy kartiny mira (modeli prostranstva, vremeni $i$ vospriyatiya) [Fragments of Russian-Language Worldview (Models of Space, Time and Perception)]. Moscow, Gnozis Publ., 1994. 344 p.

8. Landau $\mathrm{B}$. Where is what and what is where: The Language of objects in space. Lingua, 1994, vol. 82, pp. 259-296.

\section{Information About the Author}

Olga P. Ryabko, Doctor of Sciences (Philology), Professor, Department of English Language for Humanitarian Faculties, Southern Federal University, Bolshaya Sadovaya St., 33, 344082 Rostov-onDon, Russian Federation, o.ryabko@yandex.ru.

\section{Информация об авторе}

Ольга Павловна Рябко, доктор филологических наук, профессор кафедры английского языка гуманитарных факультетов, Южный федеральный университет, ул. Большая Садовая, 33, 344082 г. Ростов-на-Дону, Российская Федерация, o.ryabko@yandex.ru. 